Article

\title{
Chemical Fingerprint and Multicomponent Quantitative Analysis for the Quality Evaluation of Cyclocarya paliurus Leaves by HPLC-Q-TOF-MS
}

\author{
Yanni Cao ${ }^{1}$, Shengzuo Fang ${ }^{1,2, *}$, Zhiqi Yin ${ }^{3}$, Xiangxiang Fu ${ }^{1,2}$, Xulan Shang ${ }^{1,2}$, Wanxia Yang ${ }^{1,2}$ \\ and Huimin Yang ${ }^{3}$ \\ 1 College of Forestry, Nanjing Forestry University, Nanjing 210037, China; 182cyn@sina.com (Y.C.); \\ xxfu@njfu.edu.cn (X.F.); shangxulan@njfu.edu.cn (X.S.); yangwanxia@njfu.com.cn (W.Y.) \\ 2 Co-Innovation Center for Sustainable Forestry in Southern China, Nanjing Forestry University, \\ Nanjing 210037, China \\ 3 Department of Natural Medicinal Chemistry and State Key Laboratory of Natural Medicines, \\ China Pharmaceutical University, Nanjing 10009, China; chyzq2005@126.com (Z.Y.); \\ yanghuimin607@163.com (H.Y.) \\ * Correspondence: fangsz@njfu.edu.cn; Tel.: +86-025-8542-7305
}

Received: 22 October 2017; Accepted: 6 November 2017; Published: 7 November 2017

\begin{abstract}
Cyclocarya paliurus is an edible and medicinal plant containing various bioactive components with significant health benefits. A combinative method using high-performance liquid chromatography (HPLC) fingerprint and quantitative analysis was developed and successfully applied for characterization and quality evaluation of $C$. paliurus leaves collected from 18 geographical locations of China. For the fingerprint analysis, 21 common peaks were observed among the 18 samples, and these peaks were identified by high-performance liquid chromatography coupled with quadrupole time-of-flight mass spectrometry (HPLC-Q-TOF-MS), while a simultaneous quantification of 16 markers was conducted to interpret the variations of contents of these bioactive compounds among the $C$. paliurus leaves from different geographical locations. Quantification results showed that the contents of these sixteen investigated compounds varied greatly among the leaves from different locations. The developed new method would be a valuable reference for further study and development of this bioactive plant.
\end{abstract}

Keywords: Cyclocarya paliurus; fingerprint; HPLC-Q-TOF-MS; quantitative analysis; quality evaluation

\section{Introduction}

Cyclocarya paliurus is a monotypic genus belonging to the Juglandaceae family, which is mainly distributed in the highlands of subtropical regions in China [1]. C. paliurus is commonly called "sweet tea tree" because of the natural sweetness of its leaves. The leaves of $C$. paliurus have long been used as a nutraceutical tea for local people. In addition to being consumed as a nutraceutical tea, it has also been used for drug formulations in traditional Chinese medicine (TCM) or as ingredients of functional foods in China [2,3]. In the past decade, a great deal of modern pharmacological studies have demonstrated that leaves of $C$. paliurus possess biological functions, including enhanced antihypertensive activity, hypoglycemic activity, hypolipidemic activity, improving mental efficiency, anticancer, anti-HIV-1, antibacterial and antioxidant activity [4-13]. These potential health benefits are attributed to the bioactive compounds in the leaves of $C$. paliurus. The chemical investigations indicated that the leaves of $C$. paliurus contained abundant physiologically active compounds, such as flavonoids, phenolic acids, triterpenoids and polysaccharides $[3,6,12,14]$. It is noteworthy that several distinctive triterpene compounds named cyclocarioside I, cyclocarioside II, cyclocarioside III, 
pterocaryoside A, pterocaryoside B and cyclocaric acid B were only isolated and identified from the leaves of C. paliurus [14-17]. Since most botanical extracts have the therapeutic or preventable effects based on the synergic effects of their multiple components and multiple targets, it is insufficient to determine merely several markers of bioactive constituents in the complex botanical extracts [18]. Unfortunately, recent studies on the quality control of C. paliurus are only focused on a few selected flavonoids such as isoquercitrin, kaempferol and quercetin or a few selected triterpenoids because many marker components are not commercially available, especially some unique constituents originating from C. paliurus [19-21]. Obviously, the current analysis on bioactive constituents was insufficient to reflect the complexity and synergistic actions of multiple components in leaves of $C$. paliurus.

Chromatographic fingerprint, a comprehensive and quantifiable identification method, displays the holistic chemical profile of botanical extracts with chromatograms, spectrograms and other graphs by analytical and chemical techniques [22-24]. Chromatographic fingerprint can be used to characterize both the marker compounds and the unknown components in a complex sample. It has been widely used in the identification of authenticity, differentiation of origin and evaluation of quality of traditional Chinese medicine and other botanical products [25-28]. At present, this method has been adopted by the World Health Organization and other authorities as a strategy for quality assessment of botanical products $[18,29,30]$. Among the chromatographic fingerprinting applied to the authentication and qualitative evaluation of botanical products over the past decade, high-performance liquid chromatography (HPLC) fingerprint emerges to be the most widely used method due to its convenience and efficiency [25,31,32]. To date, little is known about the quality evaluation of C. paliurus from different geographic locations. Therefore, measurement of the whole leaf constituents of $C$. paliurus from different geographic regions is of great interest and importance through chromatographic fingerprint analysis and determination of multiple characteristic compounds.

In this present study, 18 leaf samples of $C$. paliurus grown in natural forests were collected in China. Chemical fingerprint of $C$. paliurus was established through a high-performance liquid chromatography coupled with quadrupole time-of-flight mass spectrometry (HPLC-Q-TOF-MS). The chromatograms of the extracted samples from different geographic locations were compared visually and qualitatively analyzed via MS behaviors. Similarity analysis and simultaneous quantification of 16 components in 18 leaf samples of $C$. paliurus were undertaken to evaluate the quality difference among the tested samples from different regions. The aim of this study was to provide comprehensive understandings of chemical profile, quantitative analysis and similarity evaluation of $C$. paliurus leaves from different geographic locations, which could be a valuable reference for further study and development of this plant.

\section{Results and Discussion}

\subsection{Optimization of Sample Extraction and Chromatographic Conditions}

In order to extract the bioactive substances sufficiently and obtain as much fingerprint information as possible, the extraction methods, extraction solvents and extraction time were optimized by using a univariate approach. Compared to refluxing extraction, the ultrasonic method was preferred as it was simpler and more convenient. The samples were extracted using $50 \%, 70 \%, 90 \%$ or $100 \%$ ethanol. By comparing the number of chromatographic peaks and peak areas with the extraction of different solvents, it was clear that, when $70 \%$ ethanol was employed, the peak numbers and peak areas reached the highest values. Thus, $70 \%$ ethanol was selected as the extraction solvent. The influence of the extraction time under ultrasonication on the efficiency of extraction was also investigated, in which powdered samples were extracted with $70 \%$ ethanol for 30,45 or $60 \mathrm{~min}$. When the ultrasonic extraction time was less than $45 \mathrm{~min}$, the extraction efficiency increased with the time, but the peak areas of the target compounds did not significantly increase after $45 \mathrm{~min}$. The above experiments suggested that samples were optimally extracted by the ultrasonic method with $70 \%$ ethanol for $45 \mathrm{~min}$. 
In order to obtain the most useful chemical information and better separation in the chromatograms, different HPLC parameters including the column brand, the mobile phase composition, the gradient elution procedure and the detection wavelength were optimized. Three kinds of reversed-phase columns, Phenomenex C18 column $(250 \mathrm{~mm} \times 4.6 \mathrm{~mm}, 5 \mu \mathrm{m})$, Waters X-bridge C18 column $(250 \mathrm{~mm} \times 4.6 \mathrm{~mm}, 5 \mu \mathrm{m})$ and Waters Sunfire C18 column $(250 \mathrm{~mm} \times 4.6 \mathrm{~mm}, 5 \mu \mathrm{m})$ were first evaluated and compared. The Waters X-bridge column was found to be more suitable and provided a better separation of compounds in the leaves, with a more-stable baseline than other brands of C18 columns. Besides, notable differences were observed between methanol-water and acetonitrile-water mobile phase systems. The acetonitrile-water system gave a better resolution than methanol-water. Meanwhile, $0.01 \%(v / v)$ formic acid was added to the mobile phase to improve the resolution and minimize the peak tailing of target compounds. Gradient elution was also used due to the complexity of chemical compositions in the tested leaves. In the process of gradient optimization, gradient time, gradient procedure and initial composition of the mobile phase were taken into consideration. Eventually, a satisfactory separation was attained within $100 \mathrm{~min}$ using the optimized gradient elution procedure as described in Section 3.3. However, there is still room to shorten the analytical time to achieve the same fingerprint quality by using other means, such as the faster-speed UPLC. In recent years, UPLC has been demonstrated to be a very powerful tool in chromatographic fingerprinting applications for its high resolution [28]. However, HPLC has emerged as the most widely used method in practice for its easy availability and relatively low price [25,31,32]. With respect to detection wavelength, more detectable common peaks and larger response values could be obtained at $205 \mathrm{~nm}$ due to the lack of a chromophore group in the chemical structures of triterpenoids, which show mainly terminal absorptions such as $205 \mathrm{~nm}$ in their UV spectra [21,23]. Hence, characteristic chromatographic patterns were obtained by using $205 \mathrm{~nm}$ as the detection wavelength.

\subsection{HPLC Fingerprint Establishment and Similarity Analysis}

The chromatographic fingerprints of 18 leaf samples of C. paliurus from different geographic locations are presented in Figure 1. The reference fingerprint (marked with $R$ in Figure 1) was developed with the median of 18 chromatograms to identify and evaluate the quality of $C$. paliurus leaves, and 21 peaks were extracted to be the characteristic common peaks. In general, the characteristic peaks' selection was based on the criterion that peaks found in each of the chromatograms of samples that originated from different geographic locations were well separated under the given chromatographic conditions, and that they had different relatively large peak areas on different profiles [33].

Similarity analysis was performed to evaluate the resemblance and difference of $C$. paliurus samples. As shown in Figure 1, chromatographic profiles of the tested samples were generally consistent, although the absorption intensity of some peaks and the numbers of peaks were slightly different for some samples. The values of similarity between the generated reference fingerprint and individual sample fingerprints were calculated using the similarity evaluation system. As detailed in Table 1 , the similarity values of 12 leaf samples were above 0.9 , indicating that similar chemical components were present in these samples regardless of geographic locations. However, relatively low similarity values (less than 0.9) were observed in leaf samples of S6, S10, S13, S14, S16 and S17, suggesting that chemical compositions or contents of the six samples might be different from those with a high similarity value. 


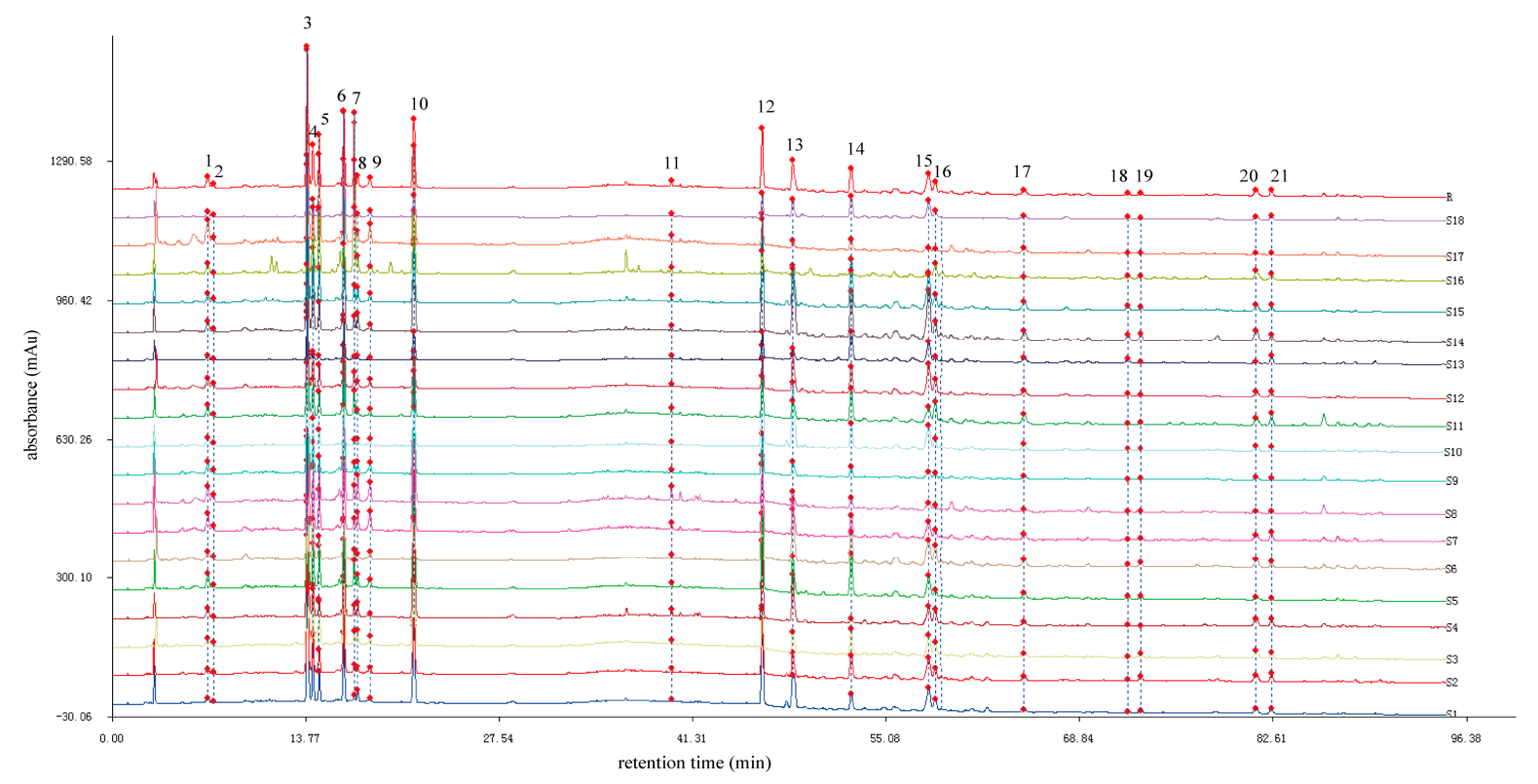

Figure 1. HPLC chromatographic fingerprints of the 18 C. paliurus samples and the reference fingerprint (R) obtained by the Similarity Evaluation System for Chromatographic Fingerprint of Traditional Chinese Medicine software (Version 2004A, Chinese Pharmacopoeia Committee, Beijing, China). The peaks marked with 1-21 represent the 21 characteristic common peaks.

Table 1. The geographical information and similarity values of leaf samples of C. paliurus.

\begin{tabular}{ccccc}
\hline Sample No. & Origins & Latitude (N) & Longitude (E) & Similarity \\
\hline S1 & Qimen, Anhui & $30^{\circ} 1^{\prime} 11^{\prime \prime}$ & $117^{\circ} 31^{\prime} 44^{\prime \prime}$ & 0.956 \\
S2 & Mingxi, Fujian & $26^{\circ} 34^{\prime} 7^{\prime \prime}$ & $116^{\circ} 33^{\prime} 46^{\prime \prime}$ & 0.987 \\
S3 & Pucheng, Fujian & $27^{\circ} 55^{\prime} 43^{\prime \prime}$ & $118^{\circ} 45^{\prime} 46^{\prime \prime}$ & 0.978 \\
S4 & Longlin, Guangxi & $24^{\circ} 21^{\prime} 36^{\prime \prime}$ & $104^{\circ} 34^{\prime} 12^{\prime \prime}$ & 0.968 \\
S5 & Longsheng, Guangxi & $25^{\circ} 22^{\prime} 12^{\prime \prime}$ & $109^{\circ} 31^{\prime} 48^{\prime \prime}$ & 0.971 \\
S6 & Liping, Guizhou & $26^{\circ} 20^{\prime} 24^{\prime \prime}$ & $109^{\circ} 14^{\prime} 24^{\prime \prime}$ & 0.836 \\
S7 & Yinjiang, Guizhou & $27^{\circ} 44^{\prime} 24^{\prime \prime}$ & $108^{\circ} 30^{\prime} 36^{\prime \prime}$ & 0.975 \\
S8 & Hefeng, Hubei & $29^{\circ} 31^{\prime} 12^{\prime \prime}$ & $110^{\circ} 15^{\prime} 00^{\prime \prime}$ & 0.926 \\
S9 & Wufeng, Hubei & $30^{\circ} 11^{\prime} 26^{\prime \prime}$ & $110^{\circ} 53^{\prime} 52^{\prime \prime}$ & 0.957 \\
S10 & Jianghua, Hunan & $24^{\circ} 55^{\prime} 2^{\prime \prime}$ & $112^{\circ} 1^{\prime} 37^{\prime \prime}$ & 0.847 \\
S11 & Nanzhao, Henan & $33^{\circ} 28^{\prime} 35^{\prime \prime}$ & $112^{\circ} 00^{\prime} 05^{\prime \prime}$ & 0.987 \\
S12 & Shangcheng, Henan & $31^{\circ} 25^{\prime} 12^{\prime \prime}$ & $115^{\circ} 19^{\prime} 12^{\prime \prime}$ & 0.917 \\
S13 & Suining, Hunan & $26^{\circ} 22^{\prime} 24^{\prime \prime}$ & $110^{\circ} 7^{\prime} 47^{\prime \prime}$ & 0.876 \\
S14 & Fenyi, Jiangxi & $27^{\circ} 22^{\prime} 12^{\prime \prime}$ & $114^{\circ} 18^{\prime} 36^{\prime \prime}$ & 0.882 \\
S15 & Xiushui, Jiangxi & $28^{\circ} 9^{\prime} 7^{\prime \prime}$ & $114^{\circ} 31^{\prime} 8^{\prime \prime}$ & 0.960 \\
S16 & Qingchuan, Sichuan & $32^{\circ} 15^{\prime} 00^{\prime \prime}$ & $104^{\circ} 30^{\prime} 36^{\prime \prime}$ & 0.523 \\
S17 & Lueyang, Shanxi & $33^{\circ} 22^{\prime} 12^{\prime \prime}$ & $105^{\circ} 50^{\prime} 24^{\prime \prime}$ & 0.888 \\
S18 & Longquan, Zhejiang & $27^{\circ} 32^{\prime} 24^{\prime \prime}$ & $119^{\circ} 6^{\prime} 36^{\prime \prime}$ & 0.936 \\
\hline
\end{tabular}

\subsection{Identification of Characteristic Common Peaks in C. paliurus Leaves}

The 21 characteristic common peaks, which were sufficient to evaluate the quality of C. paliurus leaves, were identified using HPLC-Q-TOF-MS. The identification was conducted by comparing HPLC retention time, $\mathrm{UV}$ absorption, $m / z$ of quasi-molecular ions and $\mathrm{MS}^{2}$ fragmentation patterns with those of reference substances and some previous reports. In general, quasi-molecular ions of these target compounds were exhibited as $[\mathrm{M}-\mathrm{H}]^{-}$in negative ion mode. The data of retention time, MS and $\mathrm{MS}^{2}$ fragment ions and the identification results for the peaks labeled in the chromatogram (Figure 1) are summarized in Table 2. Among the 21 characteristic common peaks, three phenolic acids, eight flavonoids and nine triterpenoids were identified or tentatively identified from leaves of C. paliurus. Moreover, 16 of these components were unambiguously identified by comparison with 
their authentic standards' retention times and $\mathrm{MS}^{2}$ data, while others were tentatively inferred based on their chromatographic behaviors and main fragments in MS ${ }^{\mathrm{n}}$ spectra, and comparing them with related literature data. The chemical structures of the 16 components are shown in Figure 2, and in addition, the chromatograms of one of the samples and the 16 mixed standards are presented in Figure 3.<smiles>[R3][C@H]1C[C@](O)(C(=O)O)C[C@@H]([R3])[C@@H]1[R2]</smiles>

$1 \mathrm{R}_{1}=3-\left(3,4-\right.$ dihydroxyphenyl)prop-2-enoyloxy, $\mathrm{R}_{2}=\mathrm{OH}, \mathrm{R}_{3}=\mathrm{OH}$ $2 \mathrm{R}_{1}=\mathrm{OH}, \mathrm{R} 2=3$-(3,4-dihydroxyphenyl)prop-2-enoyloxy, $\mathrm{R}_{3}=\mathrm{OH}$ $9 \mathrm{R}_{1}=\mathrm{OH}, \mathrm{R} 2=3$-(3,4-dihydroxyphenyl)prop-2-enoyloxy, $\mathrm{R}_{3}=3$-(3,4-dihydroxyphenyl)prop-2-enoyloxy<smiles>[R]Oc1c(-c2ccc(O)c(O)c2)oc2cc(O)cc([R1])c2c1=O</smiles><smiles>[R]Oc1c(-c2ccc(O)cc2)oc2cc(O)cc(O)c2c1=O</smiles>

$$
\begin{aligned}
& 3 R=\text { glucuronide } \\
& 4 R=\text { galactoside } \\
& 5 R=\text { glucoside } \\
& 8 R=\text { rhamnoside }
\end{aligned}
$$

$$
\begin{aligned}
& 6 R=\text { glucuronide } \\
& 7 R=\text { glucoside } \\
& 10 R=\text { rhamnoside }
\end{aligned}
$$

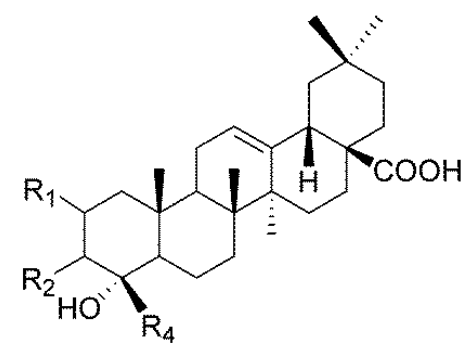

$12 \mathrm{R}_{1}=\mathrm{OH}, \mathrm{R}_{2}=\mathrm{OH}, \mathrm{R}_{3}=\mathrm{CH}_{2} \mathrm{OH}, \mathrm{R} 4=\mathrm{CH}_{3}$

$13 \mathrm{R}_{1}=\mathrm{OH}, \mathrm{R}_{2}=$ carbonyl group, $\mathrm{R} 3=\mathrm{CH}_{2} \mathrm{OH}, \mathrm{R}_{4}=\mathrm{CH}_{3}$

$16 \mathrm{R}_{1}=$ null, $\mathrm{R}_{2}=\mathrm{OH}, \mathrm{R}_{3}=\mathrm{CH}_{2} \mathrm{OH}, \mathrm{R} 4=\mathrm{CH}_{3}$

$20 \mathrm{R}_{1}=$ null, $\mathrm{R}_{2}=\mathrm{OH}, \mathrm{R}_{3}=\mathrm{CH}_{3}, \mathrm{R} 4=\mathrm{CH}_{3}$

\begin{tabular}{|c|c|c|c|c|c|}
\hline Peak No. & $t_{R}(\min )$ & {$[\mathbf{M}-\mathbf{H}]^{-}$} & MS/MS Fragment Ion $(\mathrm{m} / \mathrm{z})$ & Formula & Identification \\
\hline 1 & 7.4 & 353.9874 & 191.0554 & $\mathrm{C}_{16} \mathrm{H}_{8} \mathrm{O}_{9}$ & 3-O-Caffeoylquinic acid \\
\hline 2 & 7.8 & 353.0875 & $191.0552 ; 179.0339 ; 135.0444$ & $\mathrm{C}_{16} \mathrm{H}_{8} \mathrm{O}_{9}$ & 4-O-Caffeoylquinic acid \\
\hline 3 & 14.9 & 477.0673 & 301.0351;178.9979;151.003 & $\mathrm{C}_{21} \mathrm{H}_{18} \mathrm{O}_{13}$ & Quercetin-3-O-glucuronide \\
\hline 4 & 15.4 & 463.0888 & $301.0343 ; 271.0244 ; 178.9979 ; 151.0029$ & $\mathrm{C}_{21} \mathrm{H}_{20} \mathrm{O}_{12}$ & Quercetin-3-O-galactoside \\
\hline 5 & 15.8 & 463.0888 & $301.0338 ; 271.0239 ; 178.9981 ; 151.0029$ & $\mathrm{C}_{21} \mathrm{H}_{20} \mathrm{O}_{12}$ & Isoquercitrin \\
\hline 6 & 17.6 & 461.9727 & $286.0431 ; 285.0401 ; 113.0235 ; 85.0296$ & $\mathrm{C}_{21} \mathrm{H}_{18} \mathrm{O}_{12}$ & Kaempferol-3-O-glucuronide \\
\hline 7 & 18.5 & 447.0935 & $285.0388 ; 284.0319 ; 255.0295$ & $\mathrm{C}_{21} \mathrm{H}_{20} \mathrm{O}_{11}$ & Kaempferol-3-O-glucoside \\
\hline 8 & 18.8 & 447.0973 & $301.0337 ; 285.0388 ; 255.0294 ; 217.0133$ & $\mathrm{C}_{21} \mathrm{H}_{20} \mathrm{O}_{11}$ & Quercetin-3-O-rhamnoside \\
\hline 9 & 19.8 & 515.1199 & $353.0864 ; 191.0553 ; 179.0342 ; 135.0443$ & $\mathrm{C}_{25} \mathrm{H}_{24} \mathrm{O}_{12}$ & 4,5-di-O-Caffeoylquinic acid \\
\hline 10 & 23.4 & 431.0981 & $285.0394 ; 255.0295 ; 227.0342$ & $\mathrm{C}_{21} \mathrm{H}_{20} \mathrm{O}_{10}$ & Kaempferol-3-O-rhamnoside \\
\hline 11 & 40.8 & 577.136 & $397.2221 ; 285.0394 ; 163.0389 ; 145.0289$ & $\mathrm{C}_{30} \mathrm{H}_{26} \mathrm{O}_{12}$ & Kaempferol-3-(6"-(Z)-cinnamylglucoside) \\
\hline 12 & 47.1 & 487.3429 & $445.2942 ; 401.3056 ; 389.2698$ & $\mathrm{C}_{30} \mathrm{H}_{48} \mathrm{O}_{5}$ & Arjunolic acid \\
\hline 13 & 49.7 & 485.3275 & / & $\mathrm{C}_{30} \mathrm{H}_{46} \mathrm{O}_{5}$ & Cyclocaric acid B \\
\hline
\end{tabular}

Figure 2. Chemical structures of the 16 quantitative compounds in leaves of $C$. paliurus: (1) 3-O-caff eoylquinic acid; (2) 4-O-caffeoylquinic acid; (3) quercetin-3-O-glucuronide; (4) quercetin-3-O-galactoside; (5) isoquercitrin; (6) kaempferol-3-O-glucuronide; (7) kaempferol 3-O-glucoside; (8) quercetin-3 -O-rhamnoside; (9) 4,5-di-O-caffeoylquinic acid; (10) kaempferol-3-O-rhamnoside; (12) arjunolic acid; (13) cyclocaric acid B; (14) pterocaryoside B; (15) pterocaryoside A; (16) hederagenin; (20) oleanolic acid.

Table 2. Identification of 21 compounds from leaves of C. paliurus by developed HPLC-Q-TOF-MS. 
Table 2. Cont.

\begin{tabular}{cccccc}
\hline Peak No. & $\mathbf{t}_{\mathbf{R}}(\mathbf{m i n})$ & ${\mathbf{~ M}-\mathbf{H}]^{-}}^{-}$ & MS/MS Fragment Ion $(\mathbf{m} / \boldsymbol{z})$ & Formula & Identification \\
\hline $\mathbf{1 4}$ & 54.2 & 621.4001 & $521.3107 ; 489.3571$ & $\mathrm{C}_{35} \mathrm{H}_{58} \mathrm{O}_{9}$ & Pterocaryoside B \\
$\mathbf{1 5}$ & 60.0 & 635.4162 & $535.3265 ; 489.3573$ & $\mathrm{C}_{36} \mathrm{H}_{60} \mathrm{O}_{9}$ & Pterocaryoside A \\
$\mathbf{1 6}$ & 60.5 & 471.3481 & 145.0286 & $\mathrm{C}_{30} \mathrm{H}_{48} \mathrm{O}_{4}$ & Hederagenin \\
$\mathbf{1 7}$ & 67.2 & 621.4017 & $489.3578 ; 469.3318$ & $\mathrm{C}_{35} \mathrm{H}_{58} \mathrm{O}_{9}$ & Cyclocarioside J \\
$\mathbf{1 8}$ & 74.4 & 635.4177 & 489.3579 & $\mathrm{C}_{36} \mathrm{H}_{60} \mathrm{O}_{9}$ & Cyclocarioside III \\
$\mathbf{1 9}$ & 75.2 & 603.3894 & $521.3107 ; 489.3573 ; 471.347$ & $\mathrm{C}_{35} \mathrm{H}_{56} \mathrm{O}_{8}$ & Cyclocarioside II \\
$\mathbf{2 0}$ & 83.5 & 455.3549 & $/$ & $\mathrm{C}_{30} \mathrm{H}_{48} \mathrm{O}_{3}$ & Oleanolic acid \\
$\mathbf{2 1}$ & 84.3 & 277.2192 & $146.9664 ; 197.9641 ; 248.9617$ & $\mathrm{C}_{18} \mathrm{H}_{30} \mathrm{O}_{2}$ & Unknown \\
\hline
\end{tabular}

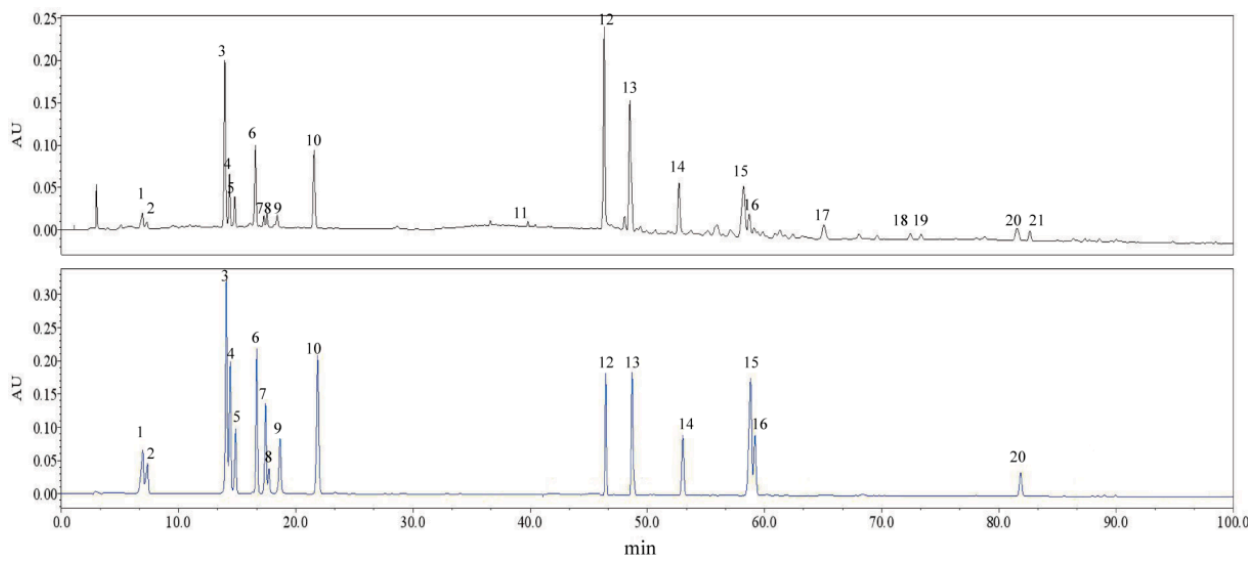

Figure 3. HPLC chromatograms of a representative sample solution (top) and a mixed standard solution containing the 16 quantitative compounds (bottom).

\subsubsection{Identification of Phenolic Acids}

Peaks 1 and 2 were identified as the esters of caffeic acid and quinic acid, respectively, and exhibited a similar $[\mathrm{M}-\mathrm{H}]^{-}$ion at $m / z 353$ and fragment ions in the $\mathrm{MS}^{2}$ scans (Table 2), but eluted at different retention times, which indicated the presence of isomers. Subsequently, they were distinguished as 3-O-caffeoylquinic acid and 4-O-caffeoylquinic acid compared with their reference standards. While peak 9 showed a $[\mathrm{M}-\mathrm{H}]^{-}$ion at $m / z 515$, which was $162 \mathrm{Da}$ more than that of peak 2, fragments at $m / z 191,179,173$ were the same as compound 2, suggesting the presence of double esters of caffeic acid. Then, it was further precisely identified as 4,5-di-O-caffeoylquinic acid by comparison with its reference compound.

\subsubsection{Identification of Flavonoids}

Flavonoids in edible and medicinal plants possess a wide range of biochemical and pharmacological effects. Many investigations of $C$. paliurus have demonstrated the presence of some flavonoid compounds in C. paliurus leaves $[6,12,19]$. In the ionization of MS analysis, the flavone aglycone was easily dissociated from the saccharidic residue, resulting in the loss of neutral ion $[\mathrm{M}-18]^{-}$. Cleavage at the glycosidic O-linkages with a concomitant H-rearrangement lead to the elimination of monosaccharide residues, that is, the loss of $162 \mathrm{Da}$ (a hexose unit), $146 \mathrm{Da}$ (a rhamnose unit) and $176 \mathrm{Da}$ (a glucuronosyl group) [34]. A total of eight flavonoid glycosides were identified in the tested samples, which were divided into two types based on their aglycones, namely quercetin and kaempferol derivatives. For example, peak 3 of a $[\mathrm{M}-\mathrm{H}]^{-}$ion at $m / z 477$ produced a dominant fragment ion at $m / z 301$ (Table 2), which was generated by the loss of a glucuronosyl group and assigned to the aglycone ion of quercetin. Thus, peak 3 was identified as quercetin-3-O-glucuronide based on its chromatographic behavior and main fragments in $\mathrm{MS}^{\mathrm{n}}$ spectra compared with literature data $[35,36]$. Consequently, the peaks of $\mathbf{4 - 8}, \mathbf{1 0}$ and $\mathbf{1 1}$ were easily identified by following the principle mentioned above with the details shown in Table 2. Moreover, they were further precisely authenticated by comparison with their reference standards except for the lack of reference standard of peak $\mathbf{1 1}$. 
By comparing the fragments with the previous literature [36], peak 11 was preliminary supposed to be kaempferol-3-(6"-(Z)-cinnamylglucoside).

\subsubsection{Identification of Triterpenoids}

Triterpenoids are another major group of bioactive components from C. paliurus. In the present study, six triterpenoids (peaks 12, 13, 14, 15, 16 and 20) were unambiguously identified by comparison with their reference standards' retention time and $\mathrm{MS}^{2}$ data, while another three compounds (peaks 17,18 and 19) were tentatively deduced based on their fragmentation pathways and previous reports of $C$. paliurus $[14,15,37,38]$. Unfortunately, we were unable to identify peak 21.

Since the ingredients in the extracts of the plant are complex, MS confirmation was needed to ascertain that the peaks represented the major compounds of this plant. HPLC-Q-TOF-MS, which provides mass measurement and fragment information, was readily available and reliable for peak identification of constituents in complex extracts of plants. Although negative and positive ion modes were complementary, the negative ion mode was selected, owing to the simplicity and stability of mass spectra, as well as lower background noise.

\subsection{Method Validation}

As shown in Table 3, the method was fully validated and all the 16 analytes demonstrated a good linearity $\left(R^{2}>0.999\right)$ within the test range. The values of LOD and LOQ were all below the level of the test samples except the 4,5-di-O-caffeoylquinic acid content of the S13 sample (Table 4), indicating the high detection sensitivity of the method. For the sixteen analytes, the RSD values of the intraday and interday precisions varied from $0.43 \%$ to $1.26 \%$ and $0.98 \%$ to $2.83 \%$, respectively, while the RSD values of repeatability were below $2.13 \%$. The mean recoveries also showed a good range of $96.5-102.9 \%$ with RSD less than $3 \%$ (Table 3).

\subsection{Quantification of Chemical Components in C. paliurus Leaves}

The amount of bioactive compounds in C. paliurus leaves is very important for the therapeutic effects. Based on the optimized method developed in this study, concentrations of 16 bioactive compounds in leaf samples of C. paliurus collected from 18 different geographic locations were determined simultaneously and the results are shown in Tables 4-6. The contents of the 16 compounds varied significantly among the 18 samples, whereas the variability was dependent on each individual compound. The differences in the contents of chemical compounds would lead to differences in their efficacies in clinical practice. In terms of phenolic acids, 3-O-caffeoylquinic acid showed high concentrations in all samples, especially in the S17 sample collected from Lueyang of Shanxi Province, reaching $2.34 \mathrm{mg} / \mathrm{g}$ (Table 4). In addition, the highest sum of the three phenolic acids was also observed in S17, followed by S8 and S7. As for flavonoids, quercetin-3-O-glucuronide, kaempferol-3-O-glucuronide and kaempferol-3-O-rhamnoside were the predominant ingredients in all samples except S16, which was from Qingchuan of Sichuan Province (Table 5). However, S16 had the highest content of kaempferol-3-O-glucoside compared with other samples, reaching $2.04 \mathrm{mg} / \mathrm{g}$. Furthermore, S16 was also rich in quercetin-3-O-galactoside and isoquercitrin. The total content of the seven flavonoids showed a great variation among different geographical locations. Among the tested samples, the samples from Hefeng of Hubei Province (S8) and Lueyang of Shanxi Province (S17) contained the highest total content (more than $10.0 \mathrm{mg} / \mathrm{g}$ ), while the sample from Suining of Hunan Province (S13) showed the lowest total amount (less than $2.10 \mathrm{mg} / \mathrm{g}$ ), indicating that the contents of phenolic compounds in C. paliurus leaves may be influenced by environmental factors or genotypes. 
Table 3. Method validation for simultaneous quantification of 16 constituents in C. paliurus leaves.

\begin{tabular}{|c|c|c|c|c|c|c|c|c|c|c|}
\hline \multirow[b]{2}{*}{ Compound } & \multirow[b]{2}{*}{ Regressive Equation $^{a}$} & \multirow[b]{2}{*}{$\begin{array}{l}\text { Linear Range } \\
\quad(\mathrm{ug} / \mathrm{mL})\end{array}$} & \multirow[b]{2}{*}{$\mathbf{R}^{2}$} & \multirow[b]{2}{*}{$\underset{(\mathrm{ng} / \mathrm{mL})}{\mathrm{LOD}}$} & \multirow[b]{2}{*}{ LOQ (ng/mL) } & \multicolumn{2}{|c|}{ Precision } & \multirow{2}{*}{$\begin{array}{c}\text { Repeatability } \\
\text { RSD } \% \\
(n=6)\end{array}$} & \multicolumn{2}{|c|}{ Recovery } \\
\hline & & & & & & $\begin{array}{c}\text { Intraday RSD } \% \\
(n=6)\end{array}$ & $\begin{array}{c}\text { Interday RSD } \% \\
(n=18)\end{array}$ & & Mean & $\begin{array}{l}\text { RSD } \% \\
(n=6)\end{array}$ \\
\hline 3-O-caffeoylquinic acid & $y=4943.9 x-37,710$ & $8-640$ & 0.9998 & 64.25 & 214.21 & 0.88 & 2.14 & 0.83 & 98.72 & 1.89 \\
\hline 4-O-caffeoylquinic acid & $y=6245.2 x-14,821$ & 4-192 & 0.9998 & 57.93 & 197.58 & 0.71 & 1.94 & 1.92 & 96.53 & 1.24 \\
\hline Quercetin-3-O-glucuronide & $y=23,136 x-119,324$ & $2.5-600$ & 0.9997 & 40.28 & 128.74 & 0.43 & 1.21 & 0.53 & 98.32 & 2.13 \\
\hline Quercetin-3-O-galactoside & $y=20,402 x-28,339$ & $2-480$ & 0.9994 & 52.94 & 174.17 & 0.48 & 1.59 & 0.92 & 102.43 & 0.92 \\
\hline Isoquercitrin & $y=21,231 x+2369.2$ & $2-180$ & 0.9997 & 58.42 & 192.52 & 0.98 & 2.35 & 1.89 & 97.89 & 2.02 \\
\hline Kaempferol-3-O-glucuronide & $y=16,702 x-92,304$ & $2-640$ & 0.9995 & 43.98 & 153.14 & 0.62 & 1.93 & 2.13 & 100.93 & 2.61 \\
\hline Kaempferol-3-O-glucoside & $y=18,066 x-87,126$ & $2-480$ & 0.9991 & 53.85 & 187.37 & 1.26 & 2.78 & 1.89 & 99.23 & 2.67 \\
\hline Quercetin-3-O-rhamnoside & $y=15,638 x-21,262$ & $2-240$ & 0.9993 & 62.48 & 199.32 & 0.49 & 0.98 & 0.57 & 98.92 & 1.95 \\
\hline 4,5-di-O-Caffeoylquinic acid & $y=9428.7 x+52,403$ & $2.5-140$ & 0.9997 & 58.97 & 201.22 & 0.63 & 1.52 & 0.82 & 101.29 & 1.82 \\
\hline Kaempferol-3-O-rhamnoside & $y=15,648 x+12,295$ & $5-150$ & 0.9997 & 64.13 & 211.81 & 0.58 & 1.68 & 1.52 & 97.69 & 1.91 \\
\hline Arjunolic acid & $y=5465.1 x+33,575$ & $5-1500$ & 0.9994 & 78.13 & 260.17 & 0.48 & 1.19 & 1.04 & 102.38 & 2.48 \\
\hline Cyclocaric acid B & $y=8579.6 x-91,948$ & $7.5-1080$ & 0.9993 & 90.16 & 296.36 & 0.92 & 2.83 & 2.05 & 102.9 & 2.52 \\
\hline Pterocaryoside B & $y=3716.1 x+52,647$ & $6.7-1608$ & 0.9991 & 72.46 & 210.27 & 1.23 & 2.42 & 2.04 & 98.19 & 2.61 \\
\hline Pterocaryoside A & $y=3746.1 x+56,466$ & $10-1200$ & 0.9991 & 86.39 & 268.62 & 0.84 & 1.96 & 1.29 & 102.85 & 1.85 \\
\hline Hederagenin & $y=6054.7 x+25,521$ & $8-640$ & 0.9997 & 72.82 & 232.3 & 0.91 & 2.53 & 1.83 & 101.83 & 1.69 \\
\hline Oleanolic acid & $y=7144.8 x+963.97$ & $1-200$ & 0.9994 & 58.41 & 185.72 & 1.23 & 2.59 & 2.43 & 98.28 & 2.93 \\
\hline
\end{tabular}

${ }^{a} y$ is the peak area, while $x$ is the concentration of each analyte $(\mathrm{ug} / \mathrm{mL})$. 
Table 4. Quantitative determination of three phenolic acids in 18 samples of C. paliurus leaves ${ }^{a}$.

\begin{tabular}{|c|c|c|c|c|}
\hline \multirow{2}{*}{ Sample No. } & \multicolumn{4}{|c|}{ Content $\left(\mathrm{mg} \mathrm{g}^{-1}\right)$} \\
\hline & 3-O-Caffeoylquinic Acid & 4-O-Caffeoylquinic Acid & 4,5-di-O-Caffeoylquinic Acid & TPC $^{b}$ \\
\hline S1 & $0.50 \pm 0.03 \mathrm{j}$ & $0.15 \pm 0.00 \mathrm{i}$ & $0.11 \pm 0.001$ & $0.77 \pm 0.04 \mathrm{~h}$ \\
\hline S3 & $0.80 \pm 0.04 \mathrm{hi}$ & $0.32 \pm 0.01 \mathrm{fg}$ & $0.22 \pm 0.01 \mathrm{f}$ & $1.34 \pm 0.07 \mathrm{f}$ \\
\hline $\mathrm{S} 4$ & $0.82 \pm 0.00 \mathrm{ghi}$ & $0.11 \pm 0.01 \mathrm{j}$ & $0.08 \pm 0.00 \mathrm{~m}$ & $1.01 \pm 0.01 \mathrm{~g}$ \\
\hline S5 & $1.31 \pm 0.00 \mathrm{~d}$ & $0.29 \pm 0.01 \mathrm{~g}$ & $0.30 \pm 0.01 \mathrm{~d}$ & $1.90 \pm 0.02 \mathrm{c}$ \\
\hline S8 & $1.42 \pm 0.01 c$ & $0.67 \pm 0.00 \mathrm{a}$ & $0.63 \pm 0.03 b$ & $2.71 \pm 0.02 b$ \\
\hline S9 & $1.00 \pm 0.01 \mathrm{e}$ & $0.34 \pm 0.02 \mathrm{f}$ & $0.32 \pm 0.02 c$ & $1.66 \pm 0.04 \mathrm{~d}$ \\
\hline $\mathrm{S} 10$ & $0.78 \pm 0.04 \mathrm{i}$ & $0.31 \pm 0.02 \mathrm{~g}$ & $0.18 \pm 0.00 \mathrm{hi}$ & $1.27 \pm 0.11 \mathrm{f}$ \\
\hline S11 & $1.00 \pm 0.05 \mathrm{e}$ & $0.22 \pm 0.01 \mathrm{~h}$ & $0.14 \pm 0.01 \mathrm{jk}$ & $1.37 \pm 0.07 f$ \\
\hline $\mathrm{S} 12$ & $0.94 \pm 0.00 \mathrm{ef}$ & $0.44 \pm 0.02 \mathrm{~d}$ & $0.21 \pm 0.00 \mathrm{fg}$ & $1.60 \pm 0.01 \mathrm{de}$ \\
\hline S13 & $0.46 \pm 0.00 \mathrm{j}$ & $0.12 \pm 0.00 \mathrm{j}$ & Trace $^{c}$ & $0.58 \pm 0.01 \mathrm{i}$ \\
\hline S18 & $0.54 \pm 0.03 \mathrm{j}$ & $0.22 \pm 0.01 \mathrm{~h}$ & $0.12 \pm 0.01 \mathrm{kl}$ & $0.88 \pm 0.08 \mathrm{gh}$ \\
\hline
\end{tabular}

${ }^{a}$ Data are expressed as mean \pm SD of duplicate experiments. Different letters indicate significant differences among the $C$. paliurus from different geographic regions in phenolic acid content $\left(p \leq 0.05\right.$ by Duncan's test); ${ }^{b}$ TPC: contents of total three phenolic acids; ${ }^{c}$ Trace: under quantification limit (LOQ).

Triterpenoids are the typical group of bioactive components from C. paliurus leaves. As shown in Table 6, arjunolic acid, cyclocaric acid B, pterocaryoside B and pterocaryoside A were found to be abundant in all samples. In addition, cyclocaric acid B, pterocaryoside B and pterocaryoside A were unique constituents detected from C. paliurus leaves, which can be used as characteristic compounds to identify the authenticity of this plant [14-17]. Our results showed that the samples from Jiangxi Province (S14 and S15) contained the highest levels of the detected triterpenoid components, followed by the samples from Liping of Guizhou province (S6) and Jianghua of Hunan Province (S10). From the view of the content of the six triterpenoid ingredients, samples from Hefeng of Hubei Province (S8), Wufeng of Hubei Province (S9), Qingchuan of Sichuan Province (S16) and Lueyang of Shanxi Province (S17) showed very low triterpenoid contents (Table 6). However, leaf samples from S8 and S17 contained high levels of phenolic acids and flavonoids (Tables 4 and 5), indicating that the response of various secondary metabolites to environment and genotype might be diverse.

In order to comprehensively evaluate the quality of $C$. paliurus leaves collected from 18 geographic locations, a hierarchical cluster analysis (HCA) was conducted using the contents of the 16 analytes and the total contents of investigated phenolic acids, flavonoids and triterpenoids as 19 variables. The result indicated that the 18 samples were classified into three distinct groups (Figure 4). Cluster 1 (including S6, S10, S14 and S15) showed high content of the tested triterpenoids. Cluster 2 (including S8, S9, S16 and S17) exhibited relatively high levels of tested phenolic acids or flavonoids, but showed lower levels of detected triterpenoids. However, cluster 3 (including 10 samples) was further divided into two subgroups (A and B, Figure 4). Samples in subgroup A (S13 and S18) showed poor performance in content of both phenolic compounds and triterpenoid compounds, whereas samples in subgroup B (including other samples) showed moderate levels of the investigated compounds. It is worth pointing out that leaf quality in woody medicinal plants could not be evaluated by chromatographic fingerprints alone based on the quantitative data and HCA results from this study. For example, S18 displayed relatively high similarity value (0.936), but the content of the three groups of the major bioactive substances were lower than other samples. On the contrary, S6, S10, S14 and S17 had high content of phenolic acids, flavonoids or triterpenoids regardless of lower similarity values. Hence, a better strategy for comprehensive quality evaluation would be using chromatographic fingerprinting combined with simultaneous quantitative techniques. 
Table 5. Quantitative determination of seven flavonoids in 18 samples of C. paliurus leaves ${ }^{a}$.

\begin{tabular}{|c|c|c|c|c|c|c|c|c|}
\hline \multirow[b]{2}{*}{ Sample No. } & \multicolumn{8}{|c|}{ Content $\left(\mathrm{mg} \mathrm{g}^{-1}\right)$} \\
\hline & $\begin{array}{l}\text { Quercetin-3-O } \\
\text {-glucuronide }\end{array}$ & $\begin{array}{l}\text { Quercetin-3-O } \\
\text {-galactoside }\end{array}$ & Isoquercitrin & $\begin{array}{l}\text { Kaempferol-3-O } \\
\text {-glucuronide }\end{array}$ & $\begin{array}{l}\text { Kaempferol-3-O } \\
\text {-glucoside }\end{array}$ & $\begin{array}{l}\text { Quercetin-3-O } \\
\text {-rhamnoside }\end{array}$ & $\begin{array}{l}\text { Kaempferol-3-O } \\
\text {-rhamnoside }\end{array}$ & $\mathrm{TFC}^{b}$ \\
\hline S1 & $2.15 \pm 0.06 c$ & $0.79 \pm 0.02 \mathrm{ab}$ & $0.37 \pm 0.02 f$ & $1.16 \pm 0.00 \mathrm{gh}$ & $0.19 \pm 0.00 \mathrm{jk}$ & $0.21 \pm 0.00 \mathrm{e}$ & $1.48 \pm 0.02 \mathrm{f}$ & $6.35 \pm 0.12 \mathrm{de}$ \\
\hline S3 & $2.09 \pm 0.11 c$ & $0.71 \pm 0.04 c$ & $0.55 \pm 0.02 \mathrm{c}$ & $1.19 \pm 0.06 \mathrm{gh}$ & $0.27 \pm 0.01 \mathrm{fg}$ & $0.24 \pm 0.01 \mathrm{~d}$ & $1.26 \pm 0.06 \mathrm{~g}$ & $6.29 \pm 0.38 \mathrm{de}$ \\
\hline S4 & $2.14 \pm 0.01 c$ & $0.42 \pm 0.01 \mathrm{f}$ & $0.20 \pm 0.01 \mathrm{i}$ & $1.39 \pm 0.03 \mathrm{e}$ & $0.24 \pm 0.00 \mathrm{~h}$ & $0.24 \pm 0.00 \mathrm{~d}$ & $2.00 \pm 0.14 \mathrm{c}$ & $6.63 \pm 0.15 \mathrm{de}$ \\
\hline S5 & $1.67 \pm 0.01 \mathrm{~d}$ & $0.55 \pm 0.00 \mathrm{~d}$ & $0.51 \pm 0.00 \mathrm{~d}$ & $1.15 \pm 0.00 \mathrm{~h}$ & $0.43 \pm 0.00 c$ & $0.22 \pm 0.00 \mathrm{e}$ & $2.17 \pm 0.08 \mathrm{~b}$ & $6.70 \pm 0.06 \mathrm{~d}$ \\
\hline S8 & $3.98 \pm 0.09 a$ & $0.46 \pm 0.00 \mathrm{e}$ & $0.53 \pm 0.01 \mathrm{~cd}$ & $2.30 \pm 0.08 a$ & $0.30 \pm 0.02 \mathrm{de}$ & $0.43 \pm 0.02 \mathrm{a}$ & $2.63 \pm 0.1 \mathrm{a}$ & $10.63 \pm 0.33 a$ \\
\hline S9 & $2.11 \pm 0.09 c$ & $0.40 \pm 0.01 \mathrm{fg}$ & $0.19 \pm 0.01 \mathrm{i}$ & $1.64 \pm 0.01 \mathrm{~d}$ & $0.21 \pm 0.01 \mathrm{ij}$ & $0.19 \pm 0.01 \mathrm{f}$ & $1.57 \pm 0.05 \mathrm{ef}$ & $6.32 \pm 0.10 \mathrm{de}$ \\
\hline $\mathrm{S} 10$ & $1.09 \pm 0.05 f$ & $0.38 \pm 0.02 \mathrm{~g}$ & $0.21 \pm 0.01 \mathrm{i}$ & $0.83 \pm 0.04 \mathrm{ij}$ & $0.16 \pm 0.011$ & $0.15 \pm 0.01 \mathrm{gh}$ & $0.82 \pm 0.041 \mathrm{i}$ & $3.65 \pm 0.18 \mathrm{~h}$ \\
\hline S11 & $1.22 \pm 0.06 \mathrm{e}$ & $0.44 \pm 0.02 \mathrm{ef}$ & $0.29 \pm 0.01 \mathrm{gh}$ & $1.17 \pm 0.06 \mathrm{gh}$ & $0.42 \pm 0.02 \mathrm{c}$ & $0.12 \pm 0.01 \mathrm{hi}$ & $1.16 \pm 0.16 \mathrm{gh}$ & $4.81 \pm 0.24 \mathrm{~g}$ \\
\hline $\mathrm{S} 12$ & $0.86 \pm 0.01 \mathrm{~g}$ & $0.41 \pm 0.01 \mathrm{fg}$ & $0.28 \pm 0.01 \mathrm{~h}$ & $1.25 \pm 0.01 \mathrm{fg}$ & $0.30 \pm 0.00 \mathrm{de}$ & $0.13 \pm 0.00 \mathrm{~h}$ & $0.57 \pm 0.01 j$ & $3.80 \pm 0.02 \mathrm{~h}$ \\
\hline $\mathrm{S} 13$ & $0.50 \pm 0.00 \mathrm{~h}$ & $0.11 \pm 0.00 \mathrm{~h}$ & $0.05 \pm 0.00 \mathrm{k}$ & $0.67 \pm 0.01 \mathrm{k}$ & $0.11 \pm 0.01 \mathrm{~m}$ & $0.08 \pm 0.00 \mathrm{j}$ & $0.55 \pm 0.01 \mathrm{j}$ & $2.07 \pm 0.02 \mathrm{i}$ \\
\hline S14 & $1.07 \pm 0.03 \mathrm{f}$ & $0.78 \pm 0.01 \mathrm{~b}$ & $0.37 \pm 0.01 \mathrm{f}$ & $1.68 \pm 0.06 \mathrm{~d}$ & $0.28 \pm 0.01 \mathrm{ef}$ & $0.30 \pm 0.00 \mathrm{~b}$ & $1.71 \pm 0.01 \mathrm{de}$ & $6.20 \pm 0.06 \mathrm{e}$ \\
\hline
\end{tabular}

${ }^{a}$ Data are expressed as mean \pm SD of duplicate experiments. Different letters indicate significant differences among the C. paliurus from different geographic regions in flavonoid content ( $p \leq 0.05$ by Duncan's test); ${ }^{b}$ TFC: content of total seven flavonoids.

Table 6. Quantitative determination of six triterpenoids in 18 samples of C. paliurus leaves ${ }^{a}$.

\begin{tabular}{|c|c|c|c|c|c|c|c|}
\hline \multirow{2}{*}{ Sample No. } & \multicolumn{7}{|c|}{ Content $\left(\mathrm{mg} \mathrm{g}^{-1}\right)$} \\
\hline & Arjunolic Acid & Cyclocaric Acid B & Pterocaryoside B & Pterocaryoside A & Hederagenin & Oleanolic Acid & TTC $^{b}$ \\
\hline S1 & $5.52 \pm 0.23 c$ & $1.00 \pm 0.05 f$ & $1.61 \pm 0.081 \mathrm{i}$ & $3.78 \pm 0.09 \mathrm{~d}$ & $1.02 \pm 0.00 \mathrm{hi}$ & $0.26 \pm 0.01 \mathrm{~h}$ & $13.18 \pm 0.49 \mathrm{e}$ \\
\hline S2 & $3.13 \pm 0.16 f$ & $1.06 \pm 0.02 \mathrm{f}$ & $2.62 \pm 0.13 \mathrm{~g}$ & $3.82 \pm 0.06 \mathrm{~d}$ & $0.96 \pm 0.01 \mathrm{i}$ & $0.40 \pm 0.00 \mathrm{e}$ & $11.99 \pm 0.53 \mathrm{fg}$ \\
\hline S3 & $2.22 \pm 0.11 \mathrm{~g}$ & $0.89 \pm 0.04 \mathrm{~g}$ & $2.62 \pm 0.13 g$ & $3.18 \pm 0.16 f$ & $1.14 \pm 0.06 \mathrm{fg}$ & $0.45 \pm 0.02 \mathrm{~d}$ & $10.50 \pm 0.20 \mathrm{~h}$ \\
\hline S4 & $4.29 \pm 0.15 \mathrm{~d}$ & $1.82 \pm 0.02 c$ & $0.46 \pm 0.03 \mathrm{k}$ & $2.89 \pm 0.14 \mathrm{fg}$ & $1.32 \pm 0.03 \mathrm{~cd}$ & $0.46 \pm 0.00 \mathrm{~d}$ & $11.24 \pm 0.20 \mathrm{gh}$ \\
\hline S5 & $4.29 \pm 0.15 \mathrm{~d}$ & $1.51 \pm 0.01 \mathrm{e}$ & $4.70 \pm 0.12 c$ & $3.49 \pm 0.09 \mathrm{e}$ & $0.65 \pm 0.03 \mathrm{k}$ & $0.17 \pm 0.00 \mathrm{i}$ & $14.79 \pm 0.45 \mathrm{~d}$ \\
\hline S6 & $5.77 \pm 0.29 b c$ & $2.17 \pm 0.00 \mathrm{~b}$ & $3.46 \pm 0.00 \mathrm{~d}$ & $4.88 \pm 0.04 c$ & $1.75 \pm 0.01 \mathrm{a}$ & $0.54 \pm 0.00 c$ & $18.57 \pm 0.54 c$ \\
\hline S7 & $3.92 \pm 0.04 \mathrm{e}$ & $1.45 \pm 0.02 \mathrm{e}$ & $2.20 \pm 0.11 \mathrm{~h}$ & $2.95 \pm 0.07 \mathrm{f}$ & $0.74 \pm 0.04 j$ & $0.37 \pm 0.00 \mathrm{f}$ & $11.62 \pm 0.34 \mathrm{fgh}$ \\
\hline S8 & $2.11 \pm 0.11 \mathrm{~g}$ & $0.70 \pm 0.02 \mathrm{~h}$ & $1.10 \pm 0.02 j$ & $1.39 \pm 0.06 \mathrm{i}$ & $0.45 \pm 0.01 \mathrm{~m}$ & $0.10 \pm 0.00 \mathrm{jk}$ & $5.85 \pm 0.21 \mathrm{k}$ \\
\hline S9 & $2.13 \pm 0.11 \mathrm{~g}$ & $0.68 \pm 0.00 \mathrm{hi}$ & $0.95 \pm 0.00 j$ & $1.05 \pm 0.05 j$ & $0.41 \pm 0.02 \mathrm{~m}$ & $0.16 \pm 0.00 \mathrm{i}$ & $5.38 \pm 0.41 \mathrm{kl}$ \\
\hline S10 & $5.98 \pm 0.02 b$ & $2.86 \pm 0.14 a$ & $2.99 \pm 0.15 f$ & $4.91 \pm 0.25 c$ & $1.10 \pm 0.06 \mathrm{gh}$ & $0.41 \pm 0.02 \mathrm{e}$ & $18.25 \pm 1.17 c$ \\
\hline S11 & $2.02 \pm 0.10 \mathrm{~g}$ & $0.85 \pm 0.04 \mathrm{~g}$ & $3.10 \pm 0.16 \mathrm{ef}$ & $2.65 \pm 0.13 g$ & $1.70 \pm 0.09 \mathrm{a}$ & $0.40 \pm 0.02 \mathrm{e}$ & $10.72 \pm 0.57 \mathrm{~h}$ \\
\hline S12 & $1.66 \pm 0.08 \mathrm{~h}$ & $1.63 \pm 0.00 \mathrm{~d}$ & $2.89 \pm 0.11 \mathrm{f}$ & $4.81 \pm 0.04 c$ & $1.40 \pm 0.03 c$ & $0.29 \pm 0.00 \mathrm{~g}$ & $12.67 \pm 0.26 \mathrm{ef}$ \\
\hline S13 & $1.62 \pm 0.01 \mathrm{~h}$ & $0.59 \pm 0.01 \mathrm{i}$ & $3.31 \pm 0.13$ de & $3.17 \pm 0.14 \mathrm{f}$ & $0.40 \pm 0.00 \mathrm{~m}$ & $0.11 \pm 0.00 \mathrm{j}$ & $9.19 \pm 0.26 \mathrm{i}$ \\
\hline S14 & $6.69 \pm 0.26 a$ & $2.80 \pm 0.06 a$ & $5.16 \pm 0.14 \mathrm{~b}$ & $8.38 \pm 0.16 a$ & $1.52 \pm 0.08 \mathrm{~b}$ & $0.67 \pm 0.00 \mathrm{a}$ & $25.22 \pm 0.30 \mathrm{a}$ \\
\hline S15 & $5.47 \pm 0.27 c$ & $1.90 \pm 0.10 c$ & $5.61 \pm 0.28 \mathrm{a}$ & $6.06 \pm 0.30 \mathrm{~b}$ & $1.26 \pm 0.02 \mathrm{de}$ & $0.36 \pm 0.01 \mathrm{f}$ & $20.67 \pm 1.03 b$ \\
\hline S16 & $1.39 \pm 0.07 \mathrm{~h}$ & $0.39 \pm 0.00 \mathrm{j}$ & $0.64 \pm 0.03 \mathrm{k}$ & $0.67 \pm 0.03 \mathrm{k}$ & $1.20 \pm 0.05 \mathrm{ef}$ & $0.59 \pm 0.02 b$ & $4.89 \pm 0.15 \mathrm{kl}$ \\
\hline S17 & $1.67 \pm 0.08 \mathrm{~h}$ & $0.43 \pm 0.01 \mathrm{j}$ & $1.17 \pm 0.03 j$ & $0.73 \pm 0.00 \mathrm{k}$ & $0.28 \pm 0.00 \mathrm{n}$ & $0.08 \pm 0.00 \mathrm{k}$ & $4.36 \pm 0.221$ \\
\hline S18 & $1.35 \pm 0.07 \mathrm{~h}$ & $0.68 \pm 0.03 \mathrm{hi}$ & $2.06 \pm 0.10 \mathrm{~h}$ & $2.27 \pm 0.11 \mathrm{~h}$ & $0.54 \pm 0.031$ & $0.17 \pm 0.00 \mathrm{i}$ & $7.08 \pm 0.35 j$ \\
\hline
\end{tabular}

${ }^{a}$ Data are expressed as mean \pm SD of duplicate experiments. Different letters indicate significant differences among the C. paliurus from different geographic regions in triterpenoid content ( $p \leq 0.05$ by Duncan's test); ${ }^{b}$ TTC: content of total six triterpenoids. 


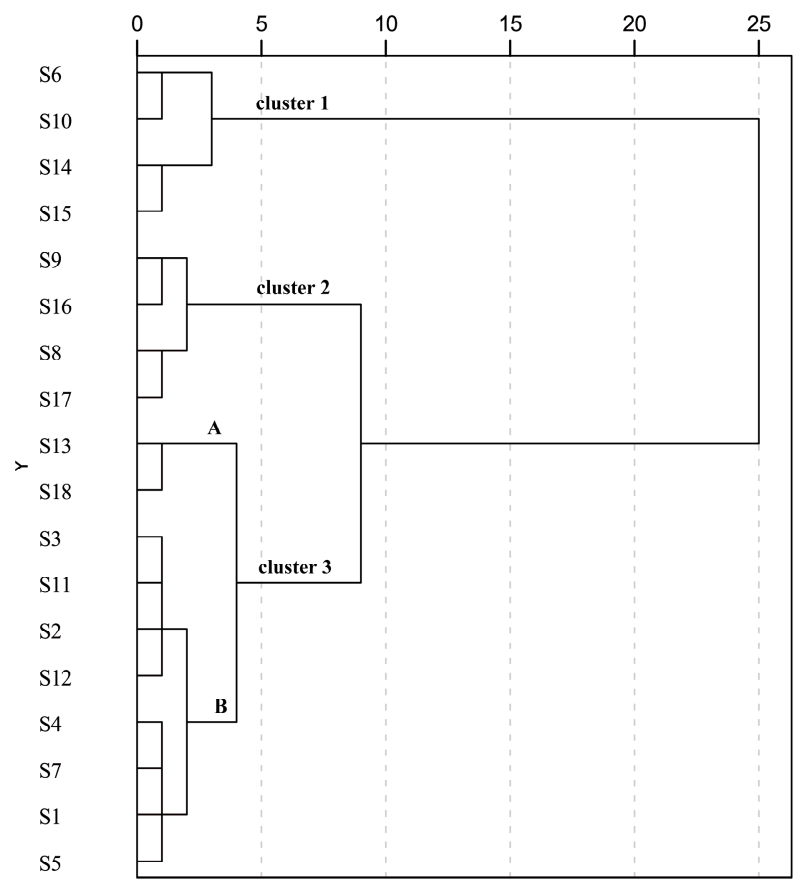

Figure 4. Dendrogram of hierarchical cluster analysis for leaf samples S1-S18 of C. paliurus (detailed geographical information for S1-S18 is listed in Table 1). A and B represent two subgroups under cluster 3 based on the squared Euclidean distance.

Accumulation of phytochemicals could be influenced by numerous internal and external factors, such as environmental conditions, genotypes and silvicultural practices during the growth period [20,39]. The most important environmental factors that affect the quantity and quality of bioactive substance are light, temperature, rainfall, latitude, soil characteristics, altitude and nutrition. Previous studies have demonstrated that light intensity significantly influences flavonoid accumulation in C. paliurus [20,40], while genetic variations could be one of the key factors affecting the biosynthesis and accumulation of bioactive compounds and quality of many medicinal plants [19,41,42]. Deng et al. has confirmed that genotype and environment significantly affect the growth and flavonoid accumulation of C. paliurus, and the interactions between environment and genotype on the accumulation of flavonoid was also observed [43]. The ancient Chinese "geoherbalism" theory, that the same plant species grown in different geographic regions may differ significantly in the specific bioactive components both qualitatively and quantitatively, also indicates the influence of interaction between environment and genotype on the accumulation of secondary metabolites. Temporal variations in natural compounds are fairly common [23,44]. Fu et al. reported that there are significant seasonal variations in the content of water-soluble polysaccharides of C. paliurus leaves [45]. To eliminate the effects of seasonal fluctuation on accumulation of bioactive compounds, the leaves tested in this study were collected at the same time for quantitative and chemical fingerprint analyses. Our results showed that the chemical profiles and contents of the 16 bioactive ingredients varied among the 18 samples from different geographical regions, suggesting that the variations might be attributed to the differences in climatic condition, soil condition and genotype. To reveal the leaf quality difference, additional investigations over the temporal, spatial and genetic variations in C. paliurus are needed. 


\section{Materials and Methods}

\subsection{Plant Materials}

18 leaf samples of C. paliurus grown in different natural forests were collected and the detailed information is shown in Table 1. At each sampling site, we collected leaves from 6 to 15 dominant trees (based on the size of natural populations) and the leaves were mixed as a batch of sample. All the leaf samples were collected in October of 2014 and were identified for authentication by the corresponding author. A voucher specimen was deposited in the Silviculture Lab of Nanjing Forestry University.

\subsection{Chemical Reagents and References}

Acetonitrile was of HPLC grade from Tedia (Fairfield, OH, USA); deionized water was further purified by a Milli-Q purification system (Millipore, Millford, MA, USA); HPLC-grade formic acid was purchased from Aladdin Co., Ltd. (Shanghai, China), and other reagents were all of analytical reagent grade. The reference standards of 3-O-caffeoylquinic acid, 4-O-caffeoylquinic acid, 4,5-di-O-caffeoylquinic acid, quercetin-3-O-glucuronide, quercetin-3-O-galactoside, isoquercitrin, kaempferol-3-O-glucuronide, kaempferol-3-O-glucoside, quercetin-3-O-rhamnoside, hederagenin and oleanolic acid were purchased from Shanghai Yuanye Biotechnology Co., Ltd. (Shanghai, China), and arjunolic acid was purchased from BioBioPha Co., Ltd. (Kunming, China), whereas kaempferol-3-O-rhamnoside, cyclocaric acid B, pterocaryoside A and pterocaryoside B were isolated and purified previously from the leaves of C. paliurus in the laboratory of China Pharmaceutical University (Nanjing, China) and were elucidated by comparison of spectral data (UV, MS, ${ }^{1} \mathrm{H}-\mathrm{NMR}$, $\left.{ }^{13} \mathrm{C}-\mathrm{NMR}\right)$ with those of published references [16,17]. The purity of each compound was determined to be more than $98 \%$ by normalization of the peak area detected by HPLC-UV.

\subsection{HPLC Instrument and Chromatographic Conditions}

All analyses were carried out on a Waters e2695 Alliance HPLC system (Waters Corp., Milford, MA, USA), equipped with a Waters 2695 separation unit (a quaternary pump solvent management system, an auto sampler, an online degasser, a column heater and a gasket cleaning system), a Waters 2489 ultraviolet detector (UVD), and an Empower 3 data processing system. The chromatographic separation was performed on an X-Bridge C18 column of $250 \times 4.6 \mathrm{~mm}$ packed with $5 \mu \mathrm{m}$ particles (Waters Corp., Milford, MA, USA). The mobile phases were composed of (A) water containing $0.01 \%(v / v)$ formic acid and $(B)$ acetonitrile containing $0.01 \%(v / v)$ formic acid with the flow rate of $1.0 \mathrm{~mL} / \mathrm{min}$. The column temperature was kept at $45^{\circ} \mathrm{C}$. The wavelength of monitor was set at $205 \mathrm{~nm}$ and the injection volume was $10.0 \mu \mathrm{L}$. The gradient elution program for C. paliurus leaves was carried out as follows: 0-13 min, 8-19\% B; 13-28 min, 19-21\% B; 28-42 min, 21-50\% B; 42-46 min, 50\% B; 46-60 min, 50-55\% B; 60-64 min, 55-56\% B; 64-74 min, 56-66\% B; 74-90 min, 66-85\% B; 90-95 min, $85-100 \% \mathrm{~B} ; 95-100 \mathrm{~min}, 100 \% \mathrm{~B}$. The post-run equilibration time of gradient elution was $15 \mathrm{~min}$.

\subsection{HPLC-Q-TOF-MS Confirmation Analysis}

Liquid chromatography (LC)-mass spectrometry (MS) analysis was carried out to confirm the peak identities. The identification was performed on an Agilent 6520 Q-TOF mass spectrometer system equipped with a diode array detector (DAD) and electrospray interface (ESI) (Agilent Technologies, Santa Clara, CA, USA). The MS system was operated in negative ionization modes with the mass scan range set at $m / z 100-1200$. The mass spectral parameters were a gas temperature of $300{ }^{\circ} \mathrm{C}$; gas flow of $10 \mathrm{~L} / \mathrm{min}$; nebulizer pressure of $30 \mathrm{psi}$; capillary voltage of $4000 \mathrm{~V}$; cone voltage of $100 \mathrm{~V}$; and collision voltage: $60 \mathrm{~V}$. The chromatographic conditions were same as those described above. Agilent Mass Hunter version B.04.00 software was used for data acquisition and processing. Peaks were identified on the basis of comparison of retention times and MS spectra with standards. 


\subsection{Sample and Standard Solution Preparation}

All leaf samples of $C$. paliurus were oven-dried at $60{ }^{\circ} \mathrm{C}$ until a constant weight was reached. Then, the leaf samples were pulverized into fine powder, and passed through a 60-mesh sieve. The sample extracts were prepared by the method of weight relief [30]. In brief, $0.8 \mathrm{~g}$ dried sample powder was accurately weighed and extracted in an ultrasonic cleaning bath (KQ250B, Kunshan Ultrasonic Instruments Co., Ltd., Kunshan, China). Ultrasonication $(44 \mathrm{kHz}, 500 \mathrm{~W})$ was performed for $45 \mathrm{~min}$ with $10 \mathrm{~mL} 70 \%(v / v)$ ethanol at $70^{\circ} \mathrm{C}$. When the extractions were cooled to room temperature, additional solvent was then added for the complement of weightlessness. After centrifugation at $10,000 \mathrm{rpm}$ for $10 \mathrm{~min}$, all extractions were filtered through a $0.22 \mu \mathrm{m}$ polytetrafluoroethylene (PTFE) filter prior to HPLC analysis.

Stock solutions were prepared by dissolving accurately weighed standards in absolute methanol. Then, the stock solutions were further diluted to appropriate concentrations for construction of calibration curves. External standard calibrations were established at six data points covering the concentration range of each compound according to the level estimated in the plant samples. The calibration curves were constructed by plotting the peak areas (UV signal) against the concentrations of each analyte. The diluted solutions of the 16 reference compounds were further diluted to a series of concentrations with methanol for obtaining the limits of detection (LOD) and quantification (LOQ). The LOD and LOQ for each marker compound under the present chromatographic conditions were separately determined at signal-to-noise $(\mathrm{S} / \mathrm{N})$ ratio of about 3 and 10, respectively. LOD and LOQ for each compound are shown in Table 1. All the solutions were stored in a refrigerator at $4{ }^{\circ} \mathrm{C}$ and brought to room temperature before use. All solutions were filtered through 0.22 um filter before injecting into HPLC.

\subsection{Method Validation}

The system precision was determined by examining six replicate injections of the same sample solution within a day and performing the procedure on three consecutive days. Six independently prepared solutions from the same sample were determined to check the repeatability. The recovery test was conducted to evaluate the accuracy of this method. The powdered sample of $C$. paliurus leaves $(0.8 \mathrm{~g})$ was accurately weighed independently six times and spiked with a known amount (approximately equivalent to 1.0 times of the amount of the actual plant leaf sample contained) of the corresponding standard compounds. Then, the spiked samples were extracted and quantified with the methods mentioned above.

\subsection{Data Analysis}

The evaluation of chromatographic fingerprint was carried out by professional software "Similarity Evaluation System for Chromatographic Fingerprint of Traditional Chinese Medicine" edited by Chinese Pharmacopoeia Committee (Version 2004A, Beijing, China). This software evaluates similarity based on calculations of correlative coefficients for fingerprint chromatographs. Quantitation of sixteen constituents was performed in duplicate for each sample, and the results were expressed as mean \pm standard deviation (SD). One-way analysis of variance (ANOVA) was used to compare the contents of the sixteen bioactive compounds in C. paliurus among different geographical sources, followed by Duncan's multiple-range test. The statistical analyses were performed at a 95\% confidence level using SPSS 19.0 software (SPSS, Chicago, IL, USA). Additionally, hierarchical cluster analysis (HCA) was conducted to classify samples from different geographic locations by using the contents of 16 analytes and the total contents of phenolic acids, flavonoids and triterpenoids as nineteen variables. In the HCA program, a dendrogram was drawn to characterize the classification results of the samples by Ward's linkage as the cluster method and squared Euclidean distance as the metric using SPSS 19.0 software. 


\section{Conclusions}

In conclusion, a combinative method using HPLC fingerprint and quantitative analysis was first developed and optimized for C. paliurus in this study, and the method was validated to be sensitive, accurate and reliable. Based on the established method, obvious variations both in chemical fingerprints and the contents of 16 bioactive ingredients were observed among the 18 samples due to various environmental factors or genotypes. Owing to the tremendous potential of utilizing the leaves of C. paliurus for food, medicine and value-added products for human health, the information provided by this study would be of great importance for authenticity identification and quality evaluation of C. paliurus leaves in the future.

Acknowledgments: This work was funded by the National Natural Science Foundation of China (No. 31470637), Jiangsu Province Science Foundation for Youths (No. BK20160926) and the Priority Academic Program Development of Jiangsu Higher Education Institutions (PAPD).

Author Contributions: Shengzuo Fang and Xiangxiang Fu conceived and designed the experiments; Xulan Shang and Wanxia Yang collected the leaf samples; Yanni Cao performed the experiments, analyzed the data and wrote the manuscript. Huimin Yang contributed some authentic standards. Shengzuo Fang and Zhiqi Yin revised the manuscript.

Conflicts of Interest: The authors declare no conflict of interest.

\section{References}

1. Fang, S.Z.; Wang, J.Y.; Wei, Z.Y.; Zhu, Z.X. Methods to break seed dormancy in Cyclocarya paliurus (Batal.) Iljinskaja. Sci. Hortic. 2006, 110, 305-309. [CrossRef]

2. Birari, R.B.; Bhutani, K.K. Pancreatic lipase inhibitors from natural source: Unexplored potential. Drug Discov. Today 2007, 12, 879-889. [CrossRef] [PubMed]

3. Xie, J.H.; Xie, M.Y.; Nie, S.P.; Shen, M.Y.; Wang, Y.X.; Li, C. Isolation, chemical composition and antioxidant activities of a watersoluble polysaccharide from Cyclocarya paliurus (Batal.) Iljinskaja. Food Chem. 2010, 119, 1626-1632. [CrossRef]

4. Hou, X.L.; Liu, X.X.; Wang, S.; Zhou, X.L.; Wei, F.; Miao, J.H. Effect of the flavonoids from Cyclocarya paliurus on spontaneous hypertension rats. Pharm. Clin. Chin. Mater. Med. 2014, 30, 62-69.

5. Kurihara, H.; Fukami, H.; Kusumoto, A.; Toyoda, Y.; Shibata, H.; Matsui, Y. Hypoglycemic action of Cyclocarya paliurus (Batal.) Iljinskaja in normal and diabetic mice. Biosci. Biotechnol. Biochem. 2003, 67, 877-880. [CrossRef] [PubMed]

6. Zhang, J.; Shen, Q.; Lu, J.C.; Li, J.Y.; Liu, W.Y.; Yang, J.J.; Li, J.; Xiao, K. Phenolic compounds from the leaves of Cyclocarya paliurus (Batal.) Ijinskaja and their inhibitory activity against PTP1B. Food Chem. 2010, 119, 1491-1496. [CrossRef]

7. Kurihara, H.; Asami, S.; Shibata, H.; Fukami, H.; Tanaka, T. Hypolipemic effect of Cyclocarya paliurus (Batal) Iljinskaja in lipid-loaded mice. Biol. Pharm. Bull. 2003, 26, 383-385. [CrossRef] [PubMed]

8. Yang, Z.W.; Ouyang, K.H.; Zhao, J.; Chen, H.; Xiong, L.; Wang, W.J. Structural characterization and hypolipidemic effect of Cyclocarya paliurus polysaccharide in rat. Int. J. Biol. Macromol. 2016, 91, 1073-1080. [CrossRef] [PubMed]

9. Wu, Z.F.; Gao, T.H.; Zhong, R.L.; Lin, Z.; Jiang, C.H.; Ouyang, S.; Zhao, M.; Che, C.T.; Zhang, J.; Yin, Z.Q. Antihyperlipidaemic effect of triterpenic acid-enriched fraction from Cyclocarya paliurus leaves in hyperlipidaemic rats. Pharm. Biol. 2017, 55, 712-721. [CrossRef] [PubMed]

10. Liu, X.; Xie, J.H.; Jia, S.; Huang, L.X.; Wang, Z.J.; Li, C.; Xie, M.Y. Immunomodulatory effects of an acetylated Cyclocarya paliurus polysaccharide on murine macrophages raw264.7. Int. J. Biol. Macromol. 2017, 98, 576-581. [CrossRef] [PubMed]

11. Xie, J.H.; Liu, X.; Shen, M.Y.; Nie, S.P.; Zhang, H.; Li, C.; Gong, D.M.; Xie, M.Y. Purification, physicochemical characterization and anticancer activity of a polysaccharide from Cyclocarya paliurus leaves. Food Chem. 2013, 136, 1453-1460. [CrossRef] [PubMed]

12. Zhang, J.; Huang, N.; Lu, J.C.; Li, X.; Wang, Y.H.; Yang, L.M.; Zheng, Y.T.; Xiao, K. Water-soluble phenolic compounds and their anti-HIV-1 activities from the leaves of Cyclocarya paliurus. J. Food Drug Anal. 2010, 18, 398-404. 
13. Xie, J.H.; Shen, M.Y.; Xie, M.Y.; Nie, S.P.; Chen, Y.; Li, C.; Huang, D.F.; Wang, Y.X. Ultrasonic-assisted extraction, antimicrobial and antioxidant activities of Cyclocarya paliurus (Batal.) Iljinskaja polysaccharides. Carbohydr. Polym. 2012, 89, 177-184. [CrossRef] [PubMed]

14. Shu, R.G.; Xu, C.R.; Li, L.N.; Yu, Z.L. Cyclocariosides II and III: Two secodammarane triterpenoid saponins from Cyclocarya paliurus. Planta Med. 1995, 61, 551-553. [CrossRef] [PubMed]

15. Shu, R.G.; Xu, C.R.; Li, L.N. Studies on the sweet principles from the leaves of Cyclocarya paliurus (Batal.) Iljinsk. Acta Pharm. Sin. 1995, 30, 757-761.

16. Kennelly, E.J.; Cai, L.; Long, L.; Shamon, L.; Zaw, K.; Zhou, B.N.; Pezzuto, J.M.; Kinghorn, A.D. Novel highly sweet secodammarane glycosides from Pterocarya paliurus. J. Agric. Food Chem. 1995, 43, 2602-2607. [CrossRef]

17. Wright, M.; Byrd, J.; Gao, Y.; Stubblefield, J.; Park, H.; Dunlap, N. Isolation and structural clarification of triterpenes from Cyclocarya paliurus: Cyclocaric acid A and B. Planta Med. 2014, 80, 139-143. [CrossRef]

18. Li, J.K.; He, X.Y.; Li, M.Y.; Zhao, W.; Liu, L.; Kong, X.H. Chemical fingerprint and quantitative analysis for quality control of polyphenols extracted from pomegranate peel by HPLC. Food Chem. 2015, 176, 7-11. [CrossRef] [PubMed]

19. Fang, S.Z.; Yang, W.X.; Chu, X.L.; Shang, X.L.; She, C.Q.; Fu, X.X. Provenance and temporal variations in selected flavonoids in leaves of Cyclocarya paliurus. Food Chem. 2011, 124, 1382-1386. [CrossRef]

20. Deng, B.; Shang, X.L.; Fang, S.Z.; Li, Q.Q.; Fu, X.X.; Su, J. Integrated effects of light intensity and fertilization on growth and flavonoid accumulation in Cyclocarya paliurus. J. Agric. Food Chem. 2012, 60, 6286-6292. [CrossRef] [PubMed]

21. Shang, X.L.; Wu, Z.F.; Yin, Z.Y.; Zhang, J.; Liu, Z.J.; Fang, S.Z. Simultaneous determination of flavonoids and triterpenoids in Cyclocarya paliurus leaves using high-performance liquid chromatography. Afr. J. Tradit. Complemt. Altern. Med. 2015, 12, 125-134. [CrossRef]

22. Gu, M.; Ouyang, F.; Su, Z.G. Comparison of high-speed counter-current chromatography and high-performance liquid chromatography on fingerprinting of Chinese traditional medicine. J. Chromatogr. A 2004, 1022, 139-144. [CrossRef] [PubMed]

23. Chou, G.X.; Xu, S.J.; Liu, D.; Koh, G.Y.; Zhang, J.; Liu, Z.J. Quantitative and fingerprint analyses of Chinese sweet tea plant (Rubus suavissimus S. Lee). J. Agric. Food Chem. 2009, 57, 1076-1083. [CrossRef] [PubMed]

24. Zhao, Y.; Sun, J.H.; Yu, L.L.; Chen, P. Chromatographic and mass spectrometric fingerprinting analyses of Angelica sinensis (Oliv.) Diels-derived dietary supplements. Anal. Bioanal. Chem. 2013, 405, 4477-4485. [CrossRef] [PubMed]

25. Tang, Z.L.; Yin, L.; Wu, F.; Zhang, X. Investigation of a novel method for quality control of Chinese herbal compound prescription: HPLC fingerprint and multi-index components combining blending technology control for quality stability of Zhou's prescription extract. Anal. Methods 2014, 6, 4158-4170. [CrossRef]

26. Yudthavorasit, S.; Wongravee, K.; Leepipatpiboon, N. Characteristic fingerprint based on gingerol derivative analysis for discrimination of ginger (Zingiber officinale) according to geographical origin using HPLC-DAD combined with chemometrics. Food Chem. 2014, 158, 101-111. [CrossRef] [PubMed]

27. Arceusz, A.; Wesolowski, M. Quality consistency evaluation of Melissa officinalis L. commercial herbs by HPLC fingerprint and quantitation of selected phenolic acids. J. Pharm. Biomed. Anal. 2013, 83, 215-220. [CrossRef] [PubMed]

28. Engström, M.T.; Pälijärvi, M.; Salminen, J.P. Rapid fingerprint analysis of plant extracts for ellagitannins, gallic acid, and quinic acid derivatives and quercetin-, kaempferol- and myricetin-based flavonol glycosides by UPLC-QqQ-MS/MS. J. Agric. Food Chem. 2015, 63, 4068-4079. [CrossRef] [PubMed]

29. Wang, J.; Cao, X.S.; Ferchaud, V.; Qi, Y.D.; Jiang, H.; Tang, F.; Yue, Y.D.; Chin, K.L. Variations in chemical fingerprints and major flavonoid contents from the leaves of thirty-one accessions of Hibiscus sabdariffa $\mathrm{L}$. Biomed. Chromatogr. 2016, 30, 880-887. [CrossRef] [PubMed]

30. Li, Y.; Wu, T.; Zhu, J.H.; Wan, L.L.; Yu, Q.; Li, X.X.; Cheng, Z.H.; Guo, C. Combinative method using HPLC fingerprint and quantitative analyses for quality consistency evaluation of an herbal medicinal preparation produced by different manufacturers. J. Pharm. Biomed. Anal. 2010, 52, 597-602. [CrossRef] [PubMed]

31. Qin, K.M.; Wang, B.; Li, W.D.; Cai, H.; Chen, D.N.; Liu, X.; Yin, F.Z.; Cai, B.C. Quality assessment of raw and processed Arctium. lappa L. through multicomponent quantification, chromatographic fingerprint, and related chemometric analysis. J. Sep. Sci. 2015, 38, 1491-1498. [CrossRef] [PubMed] 
32. Viapiana, A.; Strucklewicka, W.; Konieczynski, P.; Wesolowski, M.; Kaliszan, R. An approach based on HPLC-fingerprint and chemometrics to quality consistency evaluation of Matricaria chamomillal L. commercial samples. Front. Plant Sci. 2016, 7, 1561-1571. [CrossRef] [PubMed]

33. Ni, Y.N.; Song, R.M.; Kokot, S. Analysis of HPLC fingerprints: Discrimination of raw and processed Rhubarb samples with the aid of chemometrics. Anal. Methods 2012, 4, 171-176. [CrossRef]

34. Kite, G.C.; Porter, E.A.; Denison, F.C.; Grayer, R.J.; Veitch, N.C.; Butler, I.; Simmods, M.S.J. Data-directed scan sequence for the general assignment of $C$-glycosylflavone $O$-glycosides in plant extracts by liquid chromatography-ion trap mass spectrometry. J. Chromatogr. A 2006, 1104, 123-131. [CrossRef] [PubMed]

35. Li, Q.; Liu, Y.Q.; Han, L.F.; Liu, J.Z.; Liu, W.Y.; Feng, F.; Zhang, J.; Xie, N. Chemical constituents and quality control of two Dracocephalum species based on high-performance liquid chromatographic fingerprints coupled with tandem mass spectrometry and chemometrics. J. Sep. Sci. 2016, 39, 4071-4085. [CrossRef] [PubMed]

36. Chen, W.L.; Zhong, P.P.; Wang, Y.X. Antioxidant activities and identification of bioactive components of Cyclocarya paliurus leaves by UPLC-QTOF-MS/MS. Food Sci. 2017, 38, 122-128.

37. Cui, B.S.; Li, S. New triterpenoid saponins from the leaves of Cyclocarya paliurus. Chin. Chem. Lett. 2015, 26, 585-589. [CrossRef]

38. Jiang, C.H.; Wang, Q.Q.; Wei, Y.J.; Yao, N.; Wu, Z.F.; Ma, Y.L.; Lin, Z.; Zhao, M.; Che, C.T.; Yao, X.M.; et al. Cholesterol-lowering effects and potential mechanisms of different polar extracts from Cyclocarya paliurus leaves in hyperlipidemic mice. J. Ethnopharmacol. 2015, 176, 17-26. [CrossRef] [PubMed]

39. André, C.M.; Oufir, M.; Hoffmann, L.; Hausman, J.F.; Rogez, H.; Larondelle, Y.; Evers, D. Influence of environment and genotype on polyphenol compounds and vitro antioxidant capacity of native Andean potatoes (Solanum tuberosum L.). J. Food Compos. Anal. 2009, 22, 517-524. [CrossRef]

40. Liu, Y.; Qian, C.Y.; Ding, S.H.; Shang, X.L.; Yang, W.X.; Fang, S.Z. Effect of regime and provenance on leaf characteristics, growth and flavonoid accumulation in Cyclocarya paliurus (Batal) Iljinskaja coppices. Bot. Stud. 2016, 57, 28-40. [CrossRef] [PubMed]

41. Schmidt, S.; Zietz, M.; Schreiner, M.; Rohn, S.; Kroh, L.W.; Krumbein, A. Genotypic and climatic influence on the concentration and composition of flavonoids in kales (Brassica oleracea var. sabellica). Food Chem. 2010, 119, 1293-1299. [CrossRef]

42. Lu, J.L.; Lu, Y.J.; Niu, Y.G.; Whent, M.; Ramadan, M.F.; Costa, J.; Yu, L.L. Effect of genotype, environment, and their interaction on phytochemical compositions and antioxidant properties of soft winter wheat flour. Food Chem. 2013, 138, 454-462.

43. Deng, B.; Cao, Y.N.; Fang, S.Z.; Shang, X.L.; Yang, W.X.; Qian, C.Y. Variation and stability of growth and leaf flavonoid content in Cyclocarya paliurus across environments. Ind. Crops Prod. 2015, 76, 386-393. [CrossRef]

44. Solar, A.; Colarič, M.; Usenik, V.; Stampar, F. Seasonal variations of selected flavonoids, phenolic acids and quinones in annual shoots of common walnut (Juglans regia L.). Plant Sci. 2006, 170, 453-461. [CrossRef]

45. Fu, X.X.; Zhou, X.D.; Deng, B.; Shang, X.L.; Fang, S.Z. Seasonal and genotypic variation of water-soluble polysaccharide content in leaves of Cyclocarya paliurus. South. For. 2015, 77, 231-236.

Sample Availability: Samples of the compounds 3-O-caffeoylquinic acid, 4-O-caffeoylquinic acid, quercetin-3-Oglucuronide, quercetin-3-O-galactoside, isoquercitrin, kaempferol-3-O-glucuronide, kaempferol 3-O-glucoside, quercetin-3-O-rhamnoside, 4, 5-di-O-caffeoylquinic acid, kaempferol-3-O-rhamnoside, arjunolic acid, cyclocaric acid B, pterocaryoside B, pterocaryoside A, hederagenin and oleanolic acid are available from the authors.

(c) 2017 by the authors. Licensee MDPI, Basel, Switzerland. This article is an open access article distributed under the terms and conditions of the Creative Commons Attribution (CC BY) license (http://creativecommons.org/licenses/by/4.0/). 